\title{
The normal growth of the tracheal wall in human foetuses
}

\author{
Michał Szpinda ${ }^{1}$, Marcin Daroszewski², Anna Szpinda로 Alina Woźniak², Celestyna Mila-Kierzenkowska², \\ Piotr Flisiński ${ }^{1}$, Marcin Wiśniewski ${ }^{1}$
} 1Department of Normal Anatomy, Ludwik Rydygier Collegium Medicum in Bydgoszc
Nicolaus Copernicus University in Torun, Poland
2Department of Medical Biology, Ludwik Rydygier Collegium Medicum in Bydgoszcz,
Nicolaus Copernicus University in Torun, Poland

Submitted: 4 November 2011

Accepted: 16 December 2011

Arch Med Sci 2013; 9, 5: 922-929

DOI: 10.5114 /aoms.2012.31411

Copyright (c) 2013 Termedia \& Banach

\section{Abstract}

Introduction: Tracheal wall thickness is a substantial indicator in various pathological changes. The present study was performed to compile normative data and formulae for the tracheal wall thickness and volume at varying gestational age. Material and methods: Using anatomical dissection, digital image analysis and statistics a range of the wall thickness, proximal internal-to-external cross-sectional area ratio, and wall volume for the trachea in 73 spontaneously aborted human fetuses aged 14-25 weeks was examined.

Results: No significant male-female differences were found. The values of tracheal wall thickness ranged from $0.36 \pm 0.01 \mathrm{~mm}$ for the 14-week group to $1.23 \pm 0.17 \mathrm{~mm}$ for the 25 -week group of gestation, according to the linear function $y=-0.823$ $+0.083 \times$ age \pm 0.087 . The tracheal lumen rate, expressed as the proximal internalto-external cross-sectional area ratio, decreased from $42.61 \pm 1.11 \%$ to $26.78 \pm 4.95 \%$, according to the function $y=62.239-1.487 \times$ age \pm 3.119 . The tracheal wall volume rose from $16.28 \pm 4.18 \mathrm{~mm}^{3}$ in fetuses aged 14 weeks to $269.22 \pm 29.26 \mathrm{~mm}^{3}$ in fetuses aged 25 weeks, according to the quintic function $y=0.000052 \times$ age $^{4.894}$.

Conclusions: The tracheal wall parameters show no sexual dimorphism. The tracheal wall grows linearly in its length, and according to a quintic function in its volume. A relative decrease in the tracheal lumen at the expense of an increase in both the wall thickness and wall volume of the trachea is found during gestation.

Key words: trachea, wall thickness, wall volume, tracheal lumen rate, regression analysis.

\section{Introduction}

Advances in perinatal medicine have required an exhaustive knowledge of the normal growth of fetal airway development to determine normal and pathological criteria adapted to anatomical particularities of the fetal tracheobronchial tree [1-6]. Tracheal wall thickness is a substantial indicator in various pathological changes [7-9]. Both increased airway wall thickness and smaller airway lumen have been relatively well examined in patients with asthma or chronic obstructive pulmonary disease [10-12]. A thickened tracheo-bronchial wall, the morphological substratum of most airway diseases, can be assessed in vivo by multi-detector computed tomography [13].

\section{Corresponding author:}

Prof. Michat Szpinda

Department of Normal Anatomy

The Ludwik Rydygier

Collegium Medicum

Nicolaus Copernicus University

24 Karłowicza St

85-092 Bydgoszcz, Poland

Phone: +4852 5853705

E-mail: kizanat@cm.umk.pl 
To date, a few theoretical patterns of fetal tracheal morphometry have focused on its length [5, 14-16], external $[15,17]$ or internal $[5,14,18-22]$ transverse diameters, and external [17] or internal $[18,23]$ volumes. However, neither wall thickness nor wall volume of the trachea have been reported in human fetuses.

In order to supplement the missing information on the tracheal wall in human fetuses, our objectives were to examine: age-specific reference intervals for wall thickness, and wall volume at varying gestational ages, relative growth of the tracheal lumen, the growth curves for wall thickness and wall volume.

\section{Material and methods}

\section{Material}

The study was performed on 73 human fetuses of both sexes (39 male, 34 female) of Caucasian origin, which had been derived from spontaneous abortions or stillbirths in the years 1989-2001. The sample included fetuses which were the outcome of causes of intra-uterine growth restriction. Legal and ethical considerations were consistent with the rules of the University Research Ethics Committee (KB 189/2011). On macroscopic examination the fetuses were free of malformation affecting laryngo-tracheal structures and never intubated. The gestational age varied from 14 to 25 weeks (Table I). The fetal ages were accurately established on the basis of the following criteria: 1) gestational age based on measurements of the crown-rump length [24], 2) known date of the beginning of the last maternal menstrual period, and 3) a combination of abdominal circumference, femur length and biparietal diameter determined by early secondtrimester ultrasound scan. All specimens had been immersed in $10 \%$ neutral buffered formalin solution for 12-24 months for preservation, and then dissected under 10-fold magnification using a stereoscope with Huygens ocular.

\section{Measurements}

In each fetus, the trachea in situ with a millimetre scale was placed vertically to the optical lens axis, then recorded using a Nikon D200 camera, and digitalized to TIFF images (Figure 1). Next, digital pictures of the trachea were assessed using digital image analysis (NIS-Elements BR 3.0, Nikon), which semi-automatically estimated the four examined variables: tracheal length, wall thickness, proximal external cross-sectional area and proximal internal cross-sectional area. Digital image analysis turned out to be an excellent method of determining the parameters mentioned above, because tracheal length, tracheal wall thickness, and internal and external cross-sectional areas of the trachea could be accurately traced using a cursor.

At first, tracheal length was measured, being expressed as the distance between the superior border of the first tracheal cartilage and the tracheal bifurcation. After that the cross section was taken between the cricoid cartilage and the first tracheal ring to examine the geometry of the proximal cross-sectional area of the trachea, i.e. wall thickness, proximal external cross-sectional area, and proximal internal cross-sectional area (Figure 2). Tracheal wall thickness constituted the distance between its internal and external borders at the level of the first tracheal ring. Both internal and external cross-sectional areas of the trachea were

Table I. Distribution of fetuses studied

\begin{tabular}{|c|c|c|c|c|c|c|c|c|}
\hline \multicolumn{2}{|c|}{ Fetal age } & \multicolumn{4}{|c|}{ Crown-rump length [mm] } & \multirow[t]{2}{*}{ Number } & \multicolumn{2}{|c|}{ Sex } \\
\hline Months & $\begin{array}{c}\text { Weeks } \\
\text { [Hbd-life] }\end{array}$ & Mean & SD & Min & Max & & Male & Female \\
\hline \multirow[t]{3}{*}{4} & 14 & 79.5 & 4.3 & 76.0 & 81.0 & 2 & 1 & 1 \\
\hline & 15 & 89.3 & 6.4 & 84.0 & 93.0 & 1 & 1 & 0 \\
\hline & 16 & 103.1 & 6.3 & 96.0 & 108.0 & 2 & 1 & 1 \\
\hline \multirow[t]{4}{*}{5} & 17 & 114.0 & 7.3 & 110.0 & 123.0 & 9 & 5 & 4 \\
\hline & 18 & 129.5 & 6.8 & 124.0 & 136.0 & 10 & 5 & 5 \\
\hline & 19 & 141.9 & 5.9 & 138.0 & 149.0 & 7 & 4 & 3 \\
\hline & 20 & 155.0 & 5.2 & 152.0 & 162.0 & 13 & 7 & 6 \\
\hline \multirow[t]{4}{*}{6} & 21 & 166.4 & 4.9 & 165.0 & 174.0 & 11 & 6 & 5 \\
\hline & 22 & 178.9 & 7.2 & 175.0 & 185.0 & 5 & 2 & 3 \\
\hline & 23 & 192.9 & 7.2 & 187.0 & 195.0 & 6 & 3 & 3 \\
\hline & 24 & 201.4 & 4.2 & 199.0 & 204.0 & 5 & 3 & 2 \\
\hline \multirow[t]{2}{*}{7} & 25 & 214.8 & 4.7 & 212.0 & 217.0 & 2 & 1 & 1 \\
\hline & & Total & & & & 73 & 39 & 34 \\
\hline
\end{tabular}



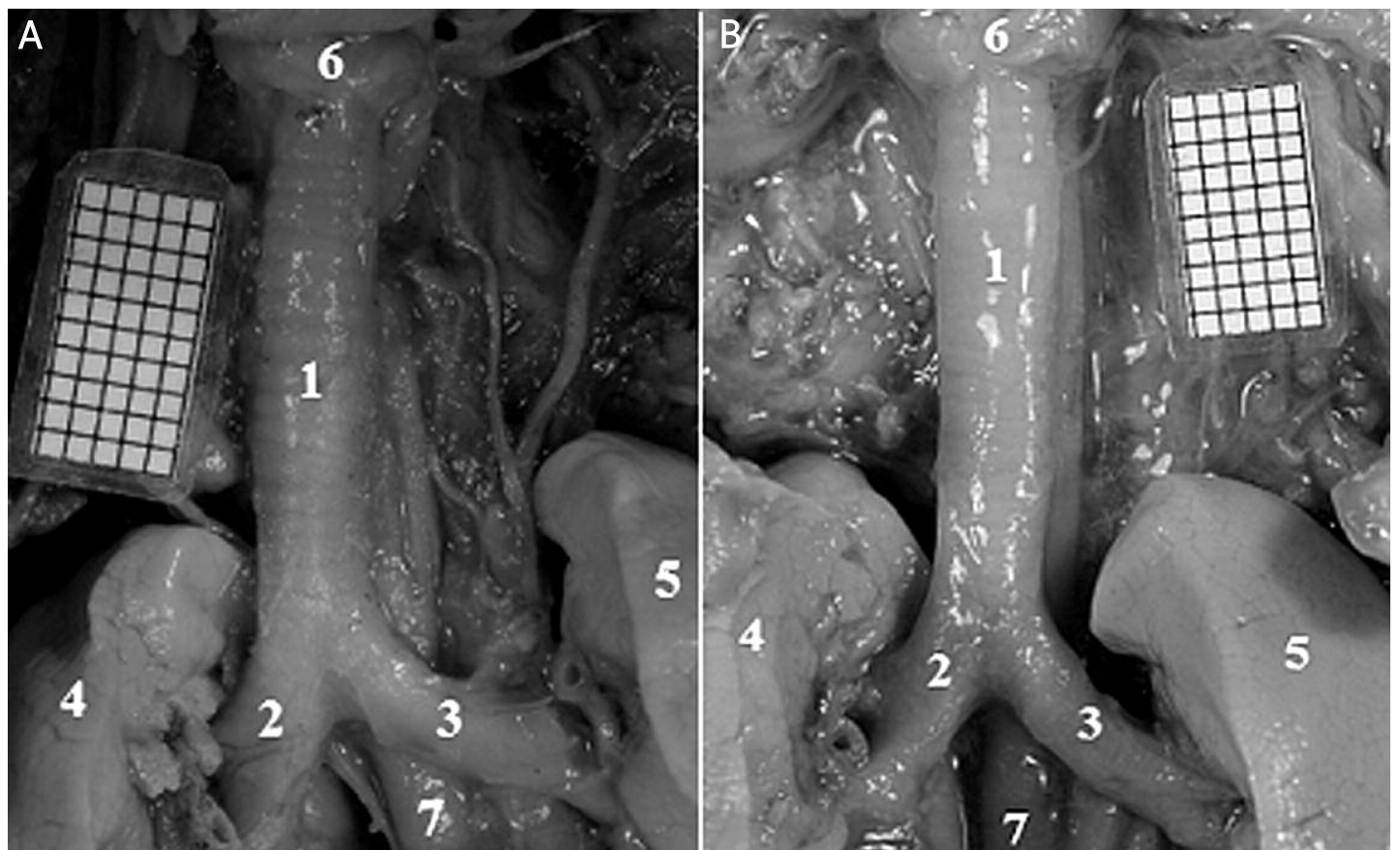

Figure 1. Topography of the trachea and main bronchi in male fetuses aged 19 weeks (A) and 23 weeks (B): 1 - trachea, 2 - right main bronchus, 3 - left main bronchus, 4 - right lung, 5 - left lung, 6 - larynx, 7 - oesophagus

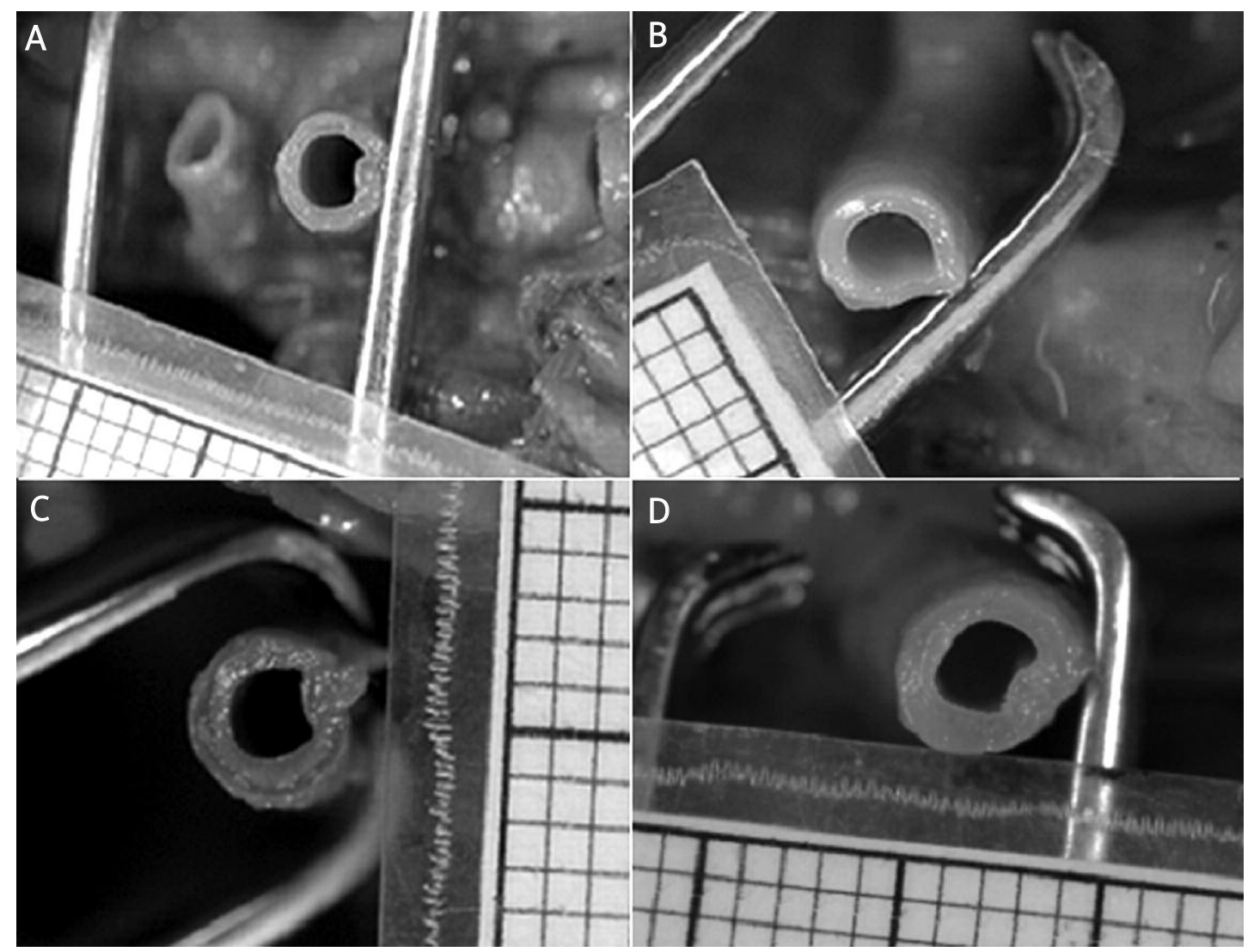

Figure 2. The trachea in cross section at the level of the first tracheal cartilage in a male fetus aged 15 weeks (A), a female fetus aged 18 weeks (B), a male fetus aged 21 weeks (C), and a female fetus aged 24 weeks (D)

semi-automatically measured, after tracing around internal and external borders of the first tracheal cartilage, respectively.
Because the size of specimens varied, we calculated the proximal internal-to-external cross-sectional area ratio, so as to express the relative growth 
of the tracheal lumen. In order to calculate the tracheal wall volume, tracheal wall thickness was assumed to be uniform in size along its length. Thus, the tracheal wall volume could be described by the following formula:

$V=V e-V i=e C S A \times l-i C S A \times l=(e C S A-i C S A) \times l$,

$V$ - tracheal wall volume, $V e$ - external volume of the trachea, $V i$ - internal volume of the trachea, eCSA - proximal external cross-sectional area, iCSA - proximal internal cross-sectional area, l - tracheal length.

For each fetus the six following measurements and calculations of the trachea were done:

- length in $\mathrm{mm}$, corresponding to the distance from the superior border of the first tracheal cartilage to the inferior border of the tracheal bifurcation,

- wall thickness in $\mathrm{mm}$, measured at the level of the first tracheal cartilage,

- proximal external cross-sectional area in $\mathrm{mm}^{2}$, traced around the external border of the first tracheal cartilage,

- proximal internal cross-sectional area in $\mathrm{mm}^{2}$, traced around the internal border of the first tracheal cartilage,

- proximal internal-to-external cross-sectional area ratio (tracheal lumen rate),

- tracheal wall volume in $\mathrm{mm}^{3}$, calculated as the product of the difference between proximal exter- nal and internal cross-sectional areas multiplied by the length.

In order to minimize measurement and observer bias, all the measurements were performed by one researcher. The mean of three repeated measurements was taken for each variable to minimize intra-observer variation.

\section{Statistical analysis}

The differences between the repeated measurements, as the intra-observer variation, were evaluated by the Wilcoxon signed-rank test. Both the tracheal wall thickness and the tracheal wall volume were plotted against fetal age so as to establish their growth. As the first step in the statistical analysis, Student's $t$-test was used to examine the influence of sex on the values of the parameters studied. Of note, the growing fetuses were separated into 12 intervals not equally distributed with respect to gestational age. Because 2 tracheas were included in the gestational ages of 14,16 and 25 weeks, and only 1 trachea in the gestational age of 15 weeks, which clearly did not represent adequate samples, the first three intervals (14-16 weeks), and the last two intervals (24-25 weeks) were separately grouped. So, in order to examine sexual differences we tested possible differences between the nine following age groups: 14-16, 17, 18, 19, 20, 21, 22, 23

Table II. Morphometric parameters of the trachea

\begin{tabular}{|c|c|c|c|c|c|c|c|}
\hline \multirow[t]{2}{*}{$\begin{array}{l}\text { Fetal age } \\
\text { [weeks] }\end{array}$} & \multirow[t]{2}{*}{$\begin{array}{l}\text { Number } \\
\text { of fetuses }\end{array}$} & \multicolumn{2}{|c|}{$\begin{array}{l}\text { Wall thickness } \\
{[\mathrm{mm}]}\end{array}$} & \multicolumn{2}{|c|}{$\begin{array}{l}\text { Proximal internal-to-external } \\
\text { cross sectional area ratio [\%] }\end{array}$} & \multicolumn{2}{|c|}{$\begin{array}{l}\text { Wall volume } \\
{\left[\mathrm{mm}^{3}\right]}\end{array}$} \\
\hline & & Mean & SD & Mean & SD & Mean & SD \\
\hline 14 & 2 & 0.36 & 0.01 & 42.61 & 1.11 & 16.28 & 4.18 \\
\hline 15 & 1 & 0.43 & 0.00 & 41.30 & 0.00 & 26.85 & 0.0 \\
\hline 16 & 2 & 0.48 & 0.08 & 40.10 & 6.90 & 32.22 & 14.14 \\
\hline 17 & 9 & $\begin{array}{c}\downarrow(p<0.01) \\
0.55 \\
\downarrow(p<0.01)\end{array}$ & 0.06 & $\begin{array}{c}\downarrow(p<0.01) \\
36.57 \\
\downarrow(p<0.05)\end{array}$ & 4.27 & $\begin{array}{c}\downarrow(p<0.01) \\
52.73 \\
\downarrow(p<0.01)\end{array}$ & 10.87 \\
\hline 18 & 10 & $\begin{array}{c}0.65 \\
\downarrow(p<0.01)\end{array}$ & 0.08 & $\begin{array}{c}36.07 \\
\downarrow(p<0.01)\end{array}$ & 3.96 & $\begin{array}{c}79.72 \\
\downarrow(p<0.01)\end{array}$ & 15.63 \\
\hline 19 & 7 & $\begin{array}{c}0.78 \\
\downarrow(p>0.05)\end{array}$ & 0.08 & $\begin{array}{c}32.02 \\
\downarrow(p<0.05)\end{array}$ & 2.48 & $\begin{array}{c}119.14 \\
\downarrow(p<0.01)\end{array}$ & 28.50 \\
\hline 20 & 13 & $\begin{array}{c}0.80 \\
\downarrow(p<0.01)\end{array}$ & 0.07 & $\begin{array}{c}31.46 \\
\downarrow(p<0.01)\end{array}$ & 2.45 & $\begin{array}{c}126.32 \\
\downarrow(p<0.01)\end{array}$ & 26.74 \\
\hline 21 & 11 & $\begin{array}{c}0.86 \\
\downarrow(p<0.01)\end{array}$ & 0.11 & $\begin{array}{c}30.67 \\
\downarrow(p<0.01)\end{array}$ & 2.69 & $\begin{array}{c}152.24 \\
\downarrow(p<0.01)\end{array}$ & 37.46 \\
\hline 22 & 5 & $\begin{array}{c}0.97 \\
\downarrow(p<0.05)\end{array}$ & 0.07 & $\begin{array}{c}29.08 \\
\downarrow(p<0.05)\end{array}$ & 3.91 & $\begin{array}{c}202.85 \\
\downarrow(p<0.01)\end{array}$ & 23.48 \\
\hline 23 & 6 & $\begin{array}{c}1.02 \\
\downarrow(p<0.01)\end{array}$ & 0.16 & $\begin{array}{c}28.77 \\
\downarrow(p<0.01)\end{array}$ & 2.54 & $\begin{array}{c}220.34 \\
\downarrow(p<0.05)\end{array}$ & 60.94 \\
\hline 24 & 5 & 1.17 & 0.11 & 27.13 & 6.48 & 247.22 & 99.38 \\
\hline 25 & 2 & 1.23 & 0.17 & 26.78 & 4.95 & 269.22 & 29.26 \\
\hline
\end{tabular}

The means in columns differ significantly $(p<0.05$ or $p<0.01)$, as indicated above 
and 24-25 weeks. Furthermore, we tested possible sex differences for the whole group, without taking into account the fetal age. In order to test whether the different variables significantly changed with age the one-way ANOVA test and post-hoc Bonferroni test were used for the nine groups (Table II). Linear and nonlinear regression analysis was used to derive the curve of best fit for each parameter against gestational age. Coefficients of determination $\left(R^{2}\right)$ between each parameter and fetal age were estimated. Differences were considered significant at $p<0.05$.

\section{Results}

No statistically significant differences were found in the evaluation of intra-observer reproducibility of the tracheal wall measurements $(p>0.05)$. In turn, inter-observer variability was not assessed since all the measurements were done by one observer. The statistical analysis showed no sexual differences $(p>0.05)$, so the numerical results without regard to sex have been presented in Table II. In contrast, the growth curves of best fit for each parameter plotted against gestational age were statistically significant $(p<0.05)$.

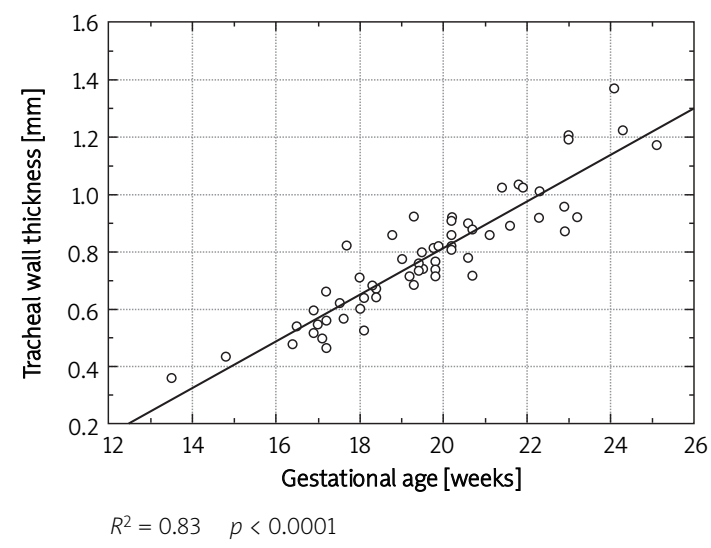

Figure 3. Regression line for tracheal wall thickness versus gestational age

A

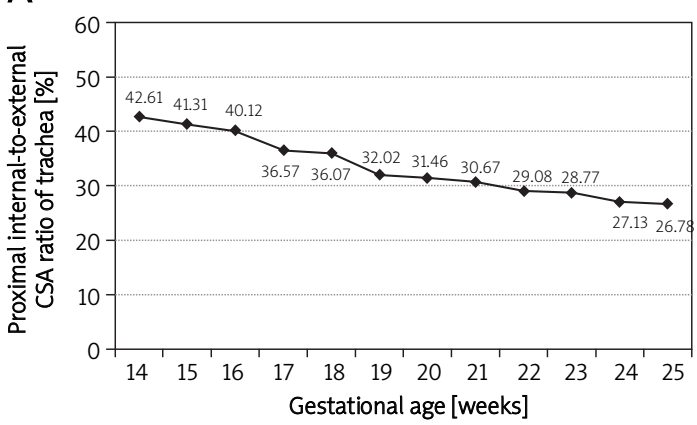

Figure 5. Tracheal wall thickness and tracheal lumen rate
The values of tracheal wall thickness ranged from $0.36 \pm 0.01 \mathrm{~mm}$ for the 14-week group to 1.23 $\pm 0.17 \mathrm{~mm}$ for the 25 -week group of gestation. The tracheal wall thickness in relation to gestational age in weeks (Figure 3) was consistent with the firstdegree polynomial (linear) function $y=-0.823+$ $0.083 \times$ age $\pm 0.087\left(R^{2}=0.83\right)$.

During the study period, the tracheal lumen rate (Figure 4), expressed as the proximal internal-toexternal cross-sectional area ratio, decreased from $42.61 \pm 1.11 \%$ to $26.78 \pm 4.95 \%$, according to the firstdegree polynomial (linear) function $y=62.239-$ $1.487 \times$ age $\pm 3.119\left(R^{2}=0.56\right)$. An increase in the tracheal wall thickness was accompanied by a decrease in the tracheal lumen (Figure 5).

At the same time, the tracheal wall volume rose from $16.28 \pm 4.18 \mathrm{~mm}^{3}$ in fetuses aged 14 weeks to $269.22 \pm 29.26 \mathrm{~mm}^{3}$ in fetuses aged 25 weeks. The numerical data of tracheal wall volume followed in accordance with the logarithmic function In $(y)$ $=-9.873+4.894 \times \ln ($ age $) \pm 0.212\left(R^{2}=0.91\right)$. After a mathematical transformation this logarithmic function was equivalent to the fifth-degree polynomial (quintic) function $y=0.000052 \times$ age $^{4.894}$ (Figure 6). Figure 7 summarizes the volumetric pro-

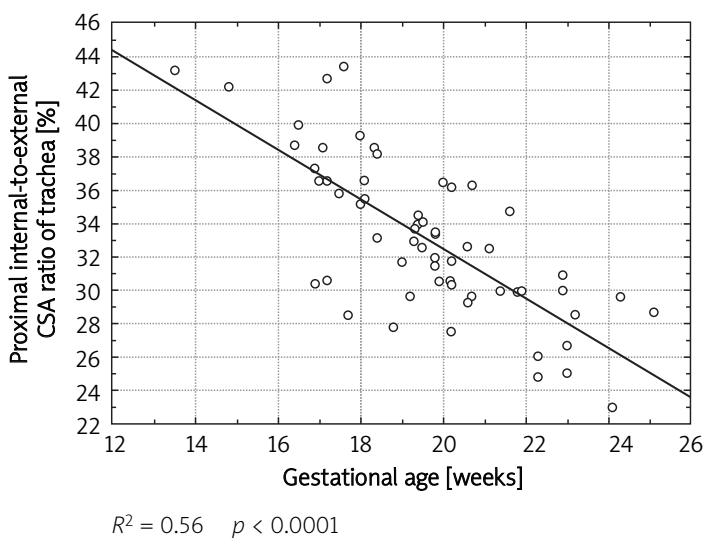

Figure 4. Tracheal lumen rate (proximal internal-toexternal cross-sectional area ratio) versus gestational age

B

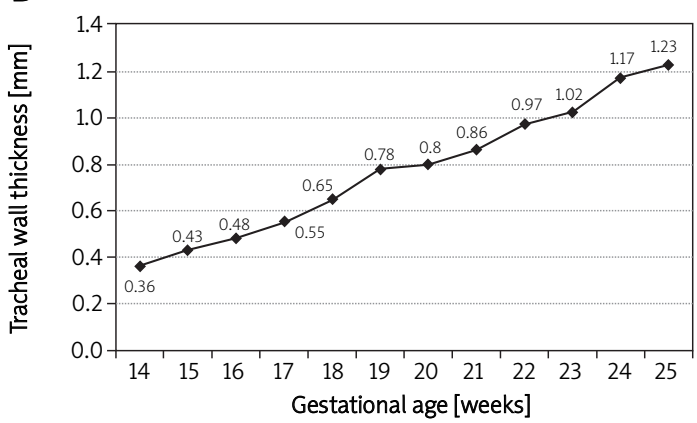




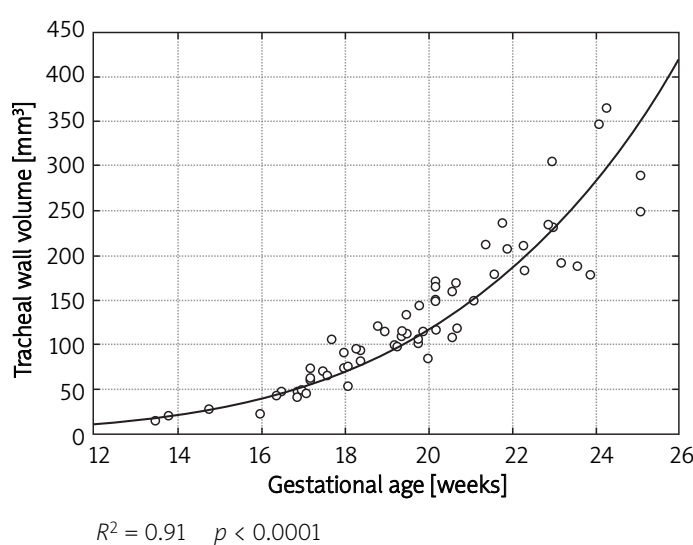

Figure 6. Tracheal wall volume versus gestational age

portions between the wall and lumen of the growing trachea in human fetuses.

\section{Discussion}

The present paper caps the morphometric study of the fetal trachea, some results of which concerning both external (length, proximal external cross-sectional area, external volume) and internal (proximal cross-sectional area, internal volume) parameters have recently been published $[17,18]$. Because of this, three tracheal parameters - length, proximal external cross-sectional area, and proximal internal cross-sectional area - were excluded from Table II. Inasmuch as wall thickness was independently measured in a direct way using digital image analysis, both the tracheal lumen rate and tracheal wall volume were not directly assessed, but calculated taking into account the results previously reported $[17,18]$. Obviously, the tracheal wall volume may have been considered as the difference between the external and internal volumes of the trachea, resulting in the formula $V=(e C S A-$ iCSA) $\times 1$.

Of note, the present data are the first to highlight the quantitative analysis of the growing tracheal wall in human fetuses. The fetal material was relatively numerous ( $n=73$ ), comparable, and representative of the studied population. Furthermore, a valid objective software package (NIS Elements BR 3.0, Nikon) was used for measuring wall thickness, the lumen rate and wall volume of the trachea. Our results have been real, because tissue shrinkage related to formalin fixation had little (0.5-1.0\%) influence on the tracheal measurements taken in situ $[25,26]$. On the other hand, isolated segments of the trachea which had been immersed in $10 \%$ formalin solution were prone to artefacts and $10 \%$ shrinkage [21].

There were no differences between males and females for tracheal wall measurements, in keeping

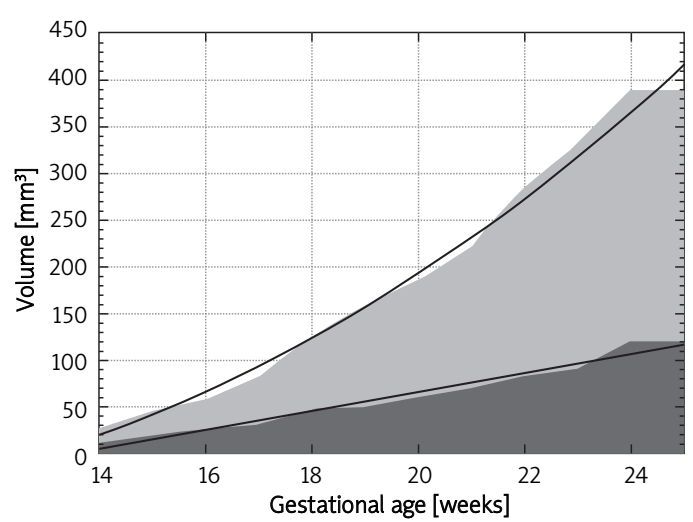

$\checkmark$ Tracheal wall volume $\square$ Internal of volume of trachea

Figure 7. Volumetric proportions between the wall and lumen of the trachea

with the results concerning other morphometric parameters such as length $[5,14,15]$, external [15, 17] or internal $[5,14,18-21]$ transverse diameters, and external [17] or internal [18, 20] volumes of the fetal trachea. Some authors $[5,20]$ reported that male and female infants and prepubertal boys and girls had similar tracheal dimensions, in spite of the fact that boys were taller. Tracheal diameters continued to grow after tracheal length had plateaued in teenage boys, and significant sexual differences in tracheal dimensions emerged as late as at puberty [20].

Anatomical measurements of tracheal wall thickness were characterized by a quasi-linear evolution from $0.36 \pm 0.01 \mathrm{~mm}$ to $1.23 \pm 0.17 \mathrm{~mm}$ for fetuses at the age of 14 and 25 weeks, respectively. The linear model chosen for age-specific reference intervals for wall thickness was $y=-0.823+0.083 x$ age \pm 0.087 , because the highest determination coefficients for possible square root $\left(R^{2}=0.26\right)$ and quadratic $\left(R^{2}=0.24\right)$ functions were much smaller than that $\left(R^{2}=0.83\right)$ of the linear one. It is noteworthy that in fetuses at ages of 14 and 25 weeks of gestation a 3-fold increase in tracheal wall thickness was accompanied by a simultaneous decrease in the tracheal lumen rate from $42.61 \pm 1.11 \%$ to 26.78 $\pm 4.95 \%$. Thus, during normal development the tracheal wall thickness increased at the expense of the decreasing tracheal lumen (Figure 5). The same trend to smaller airway lumen and increased wall thickness of the trachea has been proved in different pathological changes.

We would like to correlate the influence of tracheal thickness with particular examples of pathological changes, so as to stress the importance of our tracheal measurements. Both increased airway wall thickness and smaller airway lumen have been relatively well examined in patients with asthma, chronic obstructive pulmonary disease and cumulative smoking history $[11,12]$. The thickening and 
remodelling of large airways was reported to closely correspond with the severity of asthma $[10,11]$. The degree of airflow obstruction is caused by an enlargement of the mucous glands with increased secretion responsible for mucous plugging, atrophy or inflammation of tracheal cartilages [27].

Diesel exposure may have a key role in an increase in tracheal thickness at the expense of its luminal diameter [27, 28]. According to Nakano et al. [27] and Safak et al. [28], the tracheal walls of toll collectors were dependent on the working duration, being significantly thicker in those working for 11-15 years than 0-10 years. Of note, tracheo-bronchial wall thickening was reported in elderly smokers with no respiratory symptoms [29]. Some authors $[30,31]$ have proved in animal models that exposure to the most important air pollutant, i.e. $\mathrm{SO}_{2}$, brought about increased tracheal wall thickness due to hypertrophy of tracheal submucosal glands, epithelial mucous cell hyperplasia or metaplasia.

Tracheal involvement in many diseases is characterized by increased tracheal wall thickness due to:

- diffuse calcified nodular thickening of the tracheal wall and nodularity of its mucosa in rhinoscleroma [32],

- multiple submucosal osteocartilaginous nodules and thickening of tracheal cartilaginous rings in tracheobronchopathia osteochondroplastica [32],

- deposition of amyloid fibrils in the submucosa in tracheobronchial amyloidosis [32],

- recurrent inflammation of tracheal rings in relapsing polychondritis [32],

- granulomatous infection in tuberculosis [32],

- osseocalcineus metaplasia of the tracheal rings [32-35],

- adenoid cystic carcinomas [36].

The volumetric growth of the tracheal wall, from $16.28 \pm 4.18 \mathrm{~mm}^{3}$ in fetuses aged 14 weeks to 269.22 $\pm 29.26 \mathrm{~mm}^{3}$ in fetuses aged 25 weeks, was fitted satisfactorily in accordance with the fifth-degree polynomial (quintic) function $y=0.000052 \times$ age $e^{4.894}$. According to this model, the tracheal wall volume, as the most dynamic parameter, was strongly increasing with fetal age, by $10.57 \mathrm{~mm}^{3}$ during the 14-week period, and by $22 \mathrm{~mm}^{3}$ during the 24-week period. The lack of data on the studied parameters in the professional literature obviously limit discussion on this subject.

The main limitation of this study was the relatively narrow age range of fetuses. The equations that we propose need to be checked in fetuses with a wide age range. Another limitation of the present study was that all measurements were conducted by a single observer in a blind fashion.

This study provides completely novel, accurate data on tracheal wall thickness and tracheal wall volume at varying gestational ages. We believe that the present data, when appropriately interpreted, might be potentially useful in the diagnosis and monitoring of fetal and perinatal tracheobronchial disorders.

In conclusions, the tracheal wall parameters show no sexual dimorphism. The tracheal wall grows linearly in its length, and according to a fifthdegree polynomial function in its volume. A relative decrease in the tracheal lumen at the expense of an increase in both the wall thickness and wall volume of the trachea is found during gestation.

\section{References}

1. Wagner W, Harrison MR. Fetal operations in the head and neck area: current state. Head Neck 2002; 24: 482-90.

2. Harrison MR, Keller RL, Hawgood SB, et al. A randomized trial of fetal endoscopic tracheal occlusion for severe fetal congenital diaphragmatic hernia. N Engl J Med 2003; 349: 1916-24.

3. Jani J, Gratacós E, Greenough A, et al. Percutaneous fetal endoscopic tracheal occlusion (FETO) for severe left-sided congenital diaphragmatic hernia. Clin Obstet Gynecol 2005; 48: 910-22.

4. Kohl T, Hering R, Bauriedel G, et al. Fetoscopic and ultrasound-guided decompression of the fetal trachea in a human fetus with Fraser syndrome and congenital high airway obstruction syndrome (CHAOS) from laryngeal atresia. Ultrasound Obstet Gynecol 2006; 27: 84-8.

5. Fayoux P, Marciniak B, Devisme L, Storme L. Prenatal and early postnatal morphogenesis and growth of human laryngotracheal structures. J Anat 2008; 213: 86-92.

6. Wójcicki P, Drozdowski P. In utero surgery - current state of the art: part I. Med Sci Monit 2010; 16: RA237-44.

7. Haidopoulou K, Goutaki M, Damianidou L, Eboriadou M, Antoniadis A, Papa A. Human bocavirus infections in hospitalized Greek children. Arch Med Sci 2010; 6: 100-3.

8. Kelishadi R, Poursafa P. Air pollution and non-respiratory health hazards for children. Arch Med Sci 2010; 6: 483-95.

9. Chowdhury O, Greenough A. Neonatal ventilatory techniques - which are best for infants born at term? Arch Med Sci 2011; 7: 381-7.

10. Boser SR, Park H, Perry SF, Ménache MG, Green FH. Fractal geometry of airway remodeling in human asthma. Am J Respir Crit Care Med 2005; 172: 817-23.

11. Awadh N, Müller NL, Park CS, Abboud RT, FitzGerald JM. Airway wall thickness in patients with near fatal asthma and control groups: assessment with high resolution computed tomographic scanning. Thorax 1998; 53: 248-53.

12. Deveci F, Murat A, Turgut T, Altuntaș E, Muz MH. Airway wall thickness in patients with COPD and healthy current smokers and healthy non-smokers: assessment with high resolution computed tomographic scanning. Respiration 2004; 71: 602-10.

13. Montaudon M, Desbarats P, Berger P, de Dietrich G, Marthan R, Laurent F. Assessment of bronchial wall thickness and lumen diameter in human adults using multi-detector computed tomography: comparison with theoretical models. J Anat 2007; 211: 579-88.

14. Menu Y, Lallemand D. Determination of the normal transverse diameter of the trachea in childhood. Ann Radiol 1981; 24: 73-5.

15. Adamiec E, Dzieciołowska-Baran E, Czerwiński F, Miklaszewska D, Teul I. Prenatal development of the human trachea. Folia Morphol 2002; 61: 123-5. 
16. Harjeet, Sahni D, Batra YK, Rajeev S. Anatomical dimensions of trachea, main bronchi, subcarinal and bronchial angles in fetuses measured ex vivo. Paediatr Anaesth 2008; 18: 1029-34.

17. Szpinda M, Daroszewski M, Woźniak A, Szpinda A, MilaKierzenkowska C. Tracheal dimensions in human fetuses: an anatomical, digital and statistical study. Surg Radiol Anat 2012; 34: 317-23.

18. Szpinda M, Daroszewski M, Szpinda A, et al. New quantitative patterns of the growing trachea in human fetuses. Med Sci Monit 2012; 18: PH63-70.

19. Wailoo MP, Emery JL. Normal growth and development of the trachea. Thorax 1982; 37: 584-7.

20. Griscom NT, Wohl ME. Dimensions of the growing trachea related to age and gender. AJR Am J Roentgenol 1986; 146: 233-7.

21. Kalache KD, Franz M, Chaoui R, Bollmann R. Ultrasound measurements of the diameter of the fetal trachea, larynx and pharynx throughout gestation applicability to prenatal diagnosis of obstructive anomalies of the upper respiratory-digestive tract. Prenat Diagn 1999; 19: 211-8.

22. Dullenkopf A, Kretschmar O, Knirsch W, et al. Comparison of tracheal tube cuff diameters with internal transverse diameters of the trachea in children. Acta Anaesthesiol Scand 2006; 50: 201-5.

23. Kamel KS, Lau G, Stringer MD. In vivo and in vitro morphometry of the human trachea. Clin Anat 2009; 22: 571-9.

24. Iffy L, Jakobovits A, Westlake W, et al. Early intrauterine development: I. The rate of growth of Caucasian embryos and fetuses between the 6th and 20th weeks of gestation. Pediatrics 1975; 56: 173-86.

25. Daroszewski M. Morphometric study of the trachea and main bronchi in human fetuses. Doctoral thesis, Torun 2011; 1-171.

26. Mehta S, Myat HM. The cross-sectional shape and circumference of the human trachea. Ann R Coll Surg Engl 1984; 66: 356-8.

27. Nakano Y, Muro S, Sakai H, et al. Computed tomographic measurements of airway dimensions and emphysema in smokers. Correlation with lung function. Am J Respir Crit Care Med 2000; 162: 1102-8.

28. Safak AA, Arbak P, Yazici B, et al. Bronchial wall thickness in toll collectors. Ind Health 2010; 48: 317-23.

29. Matsuoka S, Uchiyama K, Shima H, Ueno N, Oish S, Nojiri Y. Bronchoarterial ratio and bronchial wall thickness on highresolution CT in asymptomatic subjects: correlation with age and smoking. AJR Am J Roentgenol 2003; 180: 513-8.

30. Farone A, Huang S, Paulauskis J, Kobzik L Airway neutrophilia and chemokine mRNA expression in sulfur dioxide-induced bronchitis. Am J Respir Cell Mol Biol 1995; 12: 345-50.

31. Shore S, Kobzik L, Long NC, et al. Increased airway responsiveness to inhaled methacholine in a rat model of chronic bronchitis. Am J Respir Crit Care Med 1995; 151: 1931-8.

32. Boiselle PM, Lynch DA. CT of the airways. Humana Press, Totowa 2008.

33. Sośnik H, Sośnik K. Investigations into human tracheal cartilage osseocalcineus metaplasia II. Histopathological examination of tracheal cartilages. Pol J Pathol 2009; 60: 179-8.

34. Sośnik H, Sośnik K. Investigations into human tracheal cartilage osseocalcineus metaplasia III. ventro-dorsal measurement of the thickness of human tracheal cartilages. Pol J Pathol 2010; 2: 78-82.

35. Sośnik H, Sośnik K. Investigations into human tracheal cartilage osseocalcineus metaplasia IV. Morphokinesis of tracheal cartilage retrograde lesions during the process of aging. Pol J Pathol 2010; 4: 224-8.
36. Wierzbicka M, Nowak K, Kasprzyk M, Szyfter W, Banaszewski J. A rare case of adenoid cystic carcinoma of the trachea with literature review. Kardiochir Torakochir Pol 2011; 8: 239-43. 